\begin{abstract}
Iranica
Abstracta Iranica Revue bibliographique pour le domaine irano-aryen

Volume 34-35-36 | 2017

Comptes rendus des publications de 2011-2013
\end{abstract}

\title{
Rose Jenny. Zoroastrianism. An Introduction
}

\section{Samra Azarnouche}

\section{(2) OpenEdition}

\section{Journals}

Édition électronique

URL : http://journals.openedition.org/abstractairanica/42772

DOI : 10.4000/abstractairanica.42772

ISSN : 1961-960X

Éditeur :

CNRS (UMR 7528 Mondes iraniens et indiens), Éditions de l'IFRI

\section{Référence électronique}

Samra Azarnouche, «Rose Jenny. Zoroastrianism. An Introduction», Abstracta Iranica [En ligne], Volume 34-35-36 | 2017, document 2, mis en ligne le 30 juillet 2017, consulté le 26 septembre 2020. URL : http://journals.openedition.org/abstractairanica/42772 ; DOI : https://doi.org/10.4000/ abstractairanica.42772

Ce document a été généré automatiquement le 26 septembre 2020.

Tous droits réservés 


\title{
Rose Jenny. Zoroastrianism. An Introduction
}

\author{
Samra Azarnouche
}

\section{RÉFÉRENCE}

Rose Jenny. Zoroastrianism. An Introduction. London / New York, I.B. Tauris, 2011, xxix + 303 p. (I.B. Tauris, Introductions to Religion).

1 Peut-on refléter - en quelques centaines de pages - à la fois la diversité culturelle des éléments relevant du zoroastrisme et la continuité des aspects emblématiques de cette religion depuis l'Âge du bronze jusqu'à nos jours? Si oui, comment rendre compte des divergences d'opinions aussi profondes chez les spécialistes qu'au sein même des communautés zoroastriennes iranienne et indienne? Pleinement consciente de cette double difficulté et par d'ingénieux allers-retours entre l'observateur externe et interne, l'A. nous livre une vision honnête et optimiste de la religion iranienne, non pas sous la forme triviale d'une synthèse, mais sous celle d'une mosaïque de données compilée à la fois chronologiquement et thématiquement. Cet ouvrage est composé de neuf chapitres: I. «Zoroastrians Present and Past (1-20)» s'ouvre sur la survivance d'un culte plusieurs fois millénaire, sa double articulation éthique et pratique, et les différences entre les rites actuels iraniens et indiens. Les pages sur la composition poétique des Gāthās et la cristallisation des notions avestiques, voire indo-iraniennes, dans la pensée zoroastrienne mobilisent largement les données philologiques. II. «The Ancient Persians : Truth-Tellers and Paradise-Builders » : cette partie historique tente de présenter un inventaire des données communes entre les sources achéménides et l'Avesta, ainsi qu'une possible résonnance zoroastrienne chez Platon (mythe d'Er le Pamphylien ou le jugement des morts dans Gorgias). III. «A Zoroastrian Presence from Seleucia to Sistan: The Parthian Period»: L'A. met parfaitement en lumière la persistance des infrastructures iraniennes et d'une idéologie conforme à l'Avesta, en examinant les sources gréco-romaines, bibliques, archéologiques, iconographique, et onomastiques, que les ostraca parthes de Nisa et leurs renseignements sur les 
institutions religieuses auraient avantageusement pu compléter. IV. «Eranshahr : The Sasanian Center of the World»: ce chapitre présente la géographie religieuse du monde sassanide avec la naissance de la notion poltico-religieuse de l'Empire, sans omettre les acteurs religieux et les cultes, journaliers ou funéraires. V. "The Zoroastrians of Central Asia»: s'appuyant sur la riche iconographie sogdienne (peintres, bas-reliefs), ce chapitre définit les particularités du zoroastrisme centrasiatique et sa place au sein de la pluralité religieuse de la région. VI. «GabrMahalle: Zoroastrians in Islamic Iran »: même marginalisées, les communautés zoroastriennes assurent la liaison axiale entre le passé religieux et son expression moderne, en préservant les feux sacrés, en compilant les textes majeurs et, dans une certaine mesure, en influant sur l'islam iranien. VII. « Parsipanu: Zoroastrianism in India »: ce chapitre retrace les chemins des Zoroastriens ayant migré en Inde par vagues successives, tout en gardant des liens sporadiques avec l'Iran (comme en témoignent les Rivâyat), et en renforçant leur position sous les Moghols et les institutions communautaires. VIII. «Zoroastrians Present: Revisited» dépeint une religion en mouvement, faisant face aux problèmes qu'accompagne la modernité (par ex. la démographie décroissante, les mariages mixtes, les débats entre orthodoxes et réformistes, l'apparition de mouvances para-zoroastriennes etc.). IX. "Zarathushtra Present and Past » : entre le ZaraӨuštra des Gāthās et le Ašo Zardošt d'aujourd'hui, ce chapitre reflète les multiples facettes d'un personnage tantôt symbolique, tantôt historique (ou historicisé), tout en tenant compte de la perception grecque du mage puis de sa réhabilitation européenne. Enrichi de cinq appendices, d'un glossaire et de nombreuses illustrations, cette introduction s'impose comme l'incontournable outil de tout iraniste et peut se lire comme complément à Jenny Rose, Zoroastrianism : A Guide for the Perplexed, London - New York, Continuum, 2011.

\section{AUTEURS}

\section{SAMRA AZARNOUCHE}

EPHE, Mondes iranien et indien 